\section{Farmacologia no século XX: a ciência dos medicamentos a partir da análise do livro de Goodman e Gilman}

\section{Pharmacology in the twentieth century: the science of drugs through the analysis of Goodman and Gilman's textbook}

\section{Silvia Cardoso Bittencourt}

Professora do Curso de Medicina da Universidade do Sul de Santa Catarina. Unidade Pedra Branca

Coordenadoria do Curso de Graduação em Medicina Av. Pedra Branca, 25

Cidade Universitária Pedra Branca

88137270 - Palhoça - SC - Brasil scbflor@hotmail.com

\section{Sandra Caponi}

Professora do Departamento de Saúde Pública e do Programa de Pós-graduação Interdisciplinar em Ciências Humanas da Universidade Federal de Santa Catarina (UFSC)

Campus Universitário Trindade 88040-900 - Florianópolis - SC - Brasil sandracaponi@gmail.com

\section{Sônia Maluf}

Professora do Departamento de Antropologia e dos Programas de Pós-graduação em Antropologia Social e Interdisciplinar em Ciências Humanas da UFSC. Departamento de Antropologia - Centro de Filosofia e Ciências Humanas

Campus Universitário Trindade 88040-900 - Florianópolis - SC - Brasil sonia.maluf@ufsc.br
BITTENCOURT, Silvia Cardoso; CAPONI Sandra; MALUF, Sônia. Farmacologia no século XX: a ciência dos medicamentos a partir da análise do livro de Goodman e Gilman. História, Ciências, Saúde Manguinhos, Rio de Janeiro, v.20, n.2, abr.-jun. 2013, p.499-519.

Resumo

Analisa a apresentação da farmacologia como ciência a partir do livro-texto de Louis Goodman e Alfred Gilman reeditado e reimpresso inúmeras vezes entre 1941 e 2006. Nas primeiras edições, a farmacologia é caracterizada como a ciência das drogas, relacionando-se com outras áreas do conhecimento; a história do desenvolvimento das drogas, a inserção dessa ciência no contexto social e suas relações com a indústria são destacadas. Nas outras edições, esses aspectos são menos pontuados, quase desaparecendo na 11aㅡ (2006). A abordagem dos aspectos históricos pode contribuir para a compreensão do desenvolvimento da farmacologia, assim como a abordagem das relações com a indústria e a sociedade é importante para refletir sobre os critérios de utilização dos medicamentos.

Palavras-chave: história dos medicamentos; história da farmacologia; ensino de farmacologia; análise de discurso; indústria de medicamentos.

\section{Abstract}

This article analyzes the presentation of pharmacology as a science in the textbook by Louis Goodman and Alfred Gilman, updated and reprinted many times between 1941 and 2006. In the first editions, pharmacology was characterized as the science of drugs and related to other areas of knowledge; the history of drug development, the role of this science in its social context and its relationship with industry were stressed. In the following editions, these aspects were minimized, almost disappearing in the $11^{\text {th }}$ (2006). The treatment of historical aspects may contribute to understanding the development of pharmacology, as well as the material on relationships with industry and society is important when reflecting on the criteria for using drugs.

Keywords: history of drugs; history of pharmacology; teaching of pharmacology; discourse analysis; drug industry. 
$\mathrm{O}$ propósito deste estudo é analisar de que modo a farmacologia como ciência foi apresentada a estudantes e profissionais no decorrer das várias edições de um livro-texto com projeção mundial. Além disso, identifica-se como os autores abordaram a influência da indústria farmacêutica sobre essa área de conhecimento. Weatherall (1996, p.246) afirma que "a farmacologia, a ciência das drogas, tornou-se necessária quando a primeira pessoa a ficar bêbada vislumbrou o que estava acontecendo com ele ou ela"1 ${ }^{1}$. Embora o desenvolvimento de medicamentos tenha se iniciado provavelmente há mais de cinco mil anos, foi a partir do século XVIII, com os avanços da ciência moderna, que a farmacologia se instituiu como área do conhecimento. No século XX, ela se estabeleceu como ciência básica nas instituições de ensino, e as pesquisas farmacológicas passaram a ser divulgadas em artigos científicos e livros didáticos. A divulgação científica dessa área de conhecimento acontece tanto para especialistas (farmacologistas, bioquímicos, farmacêuticos) quanto para médicos, prescritores de medicamentos.

O livro atualmente intitulado Goodman and Gilman's: the pharmacological basis of therapeutics (Brunton, Lazo, Parker, 2006) é reconhecido e utilizado em vários países como referência para estudantes, além de ser consultado por profissionais graduados que buscam atualização (Casavant, 2002, 2006; Hastings, Long, 1991; OPS, 1969). Foram analisadas 11 edições dessa obra, publicadas originalmente em inglês, entre 1941 e 2006² . A primeira edição foi em 1941 com o título The pharmacological basis of therapeutics: a textbook of pharmacology, toxicology and therapeutics for physicians and medical students (Goodman, Gilman, 1947 [1.ed. 1941]).

Os autores das primeiras edições eram Louis Goodman e Alfred Gilman, e a editora, a Mcmillan Company, na época com sede nos EUA, Canadá e Reino Unido. Décadas depois, quando deixaram de participar ativamente do processo de escrita e/ou edição, o nome dos autores foi dado à obra. Louis Goodman considerou esse livro seu maior legado, mesmo levando em conta outras contribuições pessoais importantes, como as referentes às pesquisas pioneiras de drogas contra o câncer (Altman, 2000). Uma das razões apontadas para o sucesso do livro já em sua primeira edição parece ter sido a ênfase nos aspectos históricos do desenvolvimento das drogas. Sobre a primeira edição do livro-texto, Altman (2000, p.2) informa que "a Macmillan imprimiu cautelosamente três mil cópias e prometeu aos autores uma caixa de uísque escocês caso fossem vendidas em quatro anos. Foram vendidas em seis semanas, e venderam mais de 86 mil cópias, em parte devido à ênfase na história do desenvolvimento de cada droga, que tornou grande o interesse pela leitura do livro".

Além disso, a obra consagrou-se nas décadas seguintes, ao que parece, por ter ocupado o espaço que se abrira no início do século XX para a farmacologia como disciplina de formação acadêmica. Segundo lembram os autores, "Um eminente farmacologista, comentando sobre a primeira edição muitos anos após seu aparecimento, declarou que a obra proporcionou o renascimento, ou talvez mais exatamente o 'nascimento', do ensino e da prática da farmacologia" (Goodman, Gilman, 1970, p.V.; 1975, p.V, destaque do original).

As diferentes edições do livro foram abordadas a partir do olhar mediado pela análise de discurso (Orlandi, 1999, 2005; Nogueira, 2001, 2008; Van Dijk, 1992, 1999). Foram analisados os prefácios, os índices e as seções ou capítulos que tratavam dos medicamentos de forma geral, da farmacologia como ciência e suas subdivisões (farmacocinética, farmacodinâmica), efeitos adversos e toxicologia. A contribuição dessa abordagem é colocar o pesquisador em 
estado de reflexão para, mesmo não estando consciente de tudo o que pode estar significando o texto, poder interpretá-lo (Orlandi, 1999). Não se afirma esta ou aquela interpretação, mas aponta-se para opacidades (Orlandi, 2005), para o 'não dito', que nos contextos discursivos têm significado importante (Nogueira, 2001, 2008). Nessa direção, observam-se as estratégias discursivas, que incluem tanto questões relacionadas ao contexto, como a questão subjetiva da credibilidade do autor, quanto a estruturação do texto, por exemplo, a disposição dos temas nos capítulos e seções, a forma como esses temas são apresentados ou o local em que a informação é colocada (Van Dijk, 1999). Assim, no livro de farmacologia, a ordem de determinados tópicos ou a não explicação de alguns conceitos refletem a importância que cada tema ocupa num momento histórico específico. Esses fatores foram levados em conta na análise, além do conteúdo escrito propriamente dito.

\section{Origens e campo de atuação da farmacologia}

Se o impulso para o nascimento da farmacologia ocorreu no século XVIII, foi no final do XIX que essa ciência teve seu desenvolvimento incrementado com as novas tecnologias disponíveis. Na metade do século XIX, na França, vale destacar as pesquisas de Claude Bernard (Porter, 2004, 1996; Black, 1999) na área de fisiologia. Ele conseguiu identificar, ao estudar a ação do curare $^{3}$, o local de atuação dessa substância no músculo animal. Embora desconhecendo a estrutura química das substâncias que atuavam na placa motora (local da terminação nervosa no músculo), percebeu que elas agiam nesse local específico. A partir dessa constatação, surgiu um conceito fundamental em farmacologia: o organismo possui receptores para drogas que, mesmo não visualizados na época por não haver recursos técnicos disponíveis, inauguraram a ideia de que a ação dos medicamentos é um evento químico (Weatherall, 1996).

Outro país em que se desenvolveu de forma intensa a pesquisa química e, depois, farmacológica foi a Alemanha (Porter, 1996), onde atuou Oswald Schmiedeberg, considerado o "pai da farmacologia" (Dagognet, Pignarre, 2005, p.232; Scheindlin, 2001). Em 1847, depois das pesquisas de Claude Bernard, apareceu a primeira cadeira de farmacologia como ciência 'de laboratório', separada das demais, na universidade de Dorpat, na Estônia. Foi professor, na ocasião da criação dessa disciplina, Rudolph Buchheim, que teve como sucessor Oswald Schmiedeberg, em 1869. Este último foi para a Alemanha em 1872 (Scheindlin, 2001; Weatherall, 1996) e, ao contrário de Buchheim, que montara um laboratório com seus próprios recursos, recebeu incentivos governamentais para criar um instituto de farmacologia. Parece situar-se aqui o primeiro grande ponto de expansão dessa nova ciência. Schmiedeberg treinou a maior parte dos médicos que foram professores de farmacologia; um aluno seu, John Jacob Abel, foi fundador da primeira cadeira de farmacologia nos EUA, em Michigan, 1890. Logo em seguida, em 1893, esse pesquisador transferiu-se para a Johns Hopkins University (Scheidlin, 2001). Foi inicialmente nos EUA, em universidades como essa, no final do século XIX, que ciências básicas desenvolvidas no laboratório passaram a fazer parte da formação médica (Coelho, 1995; Weatherall, 1996).

Na Alemanha, o médico Paul Ehrlich, mais interessado em estudar os tecidos celulares do que em atuar na prática clínica, introduziu em 1900 o termo receptor para nomear o que Claude Bernard vislumbrara décadas antes. O termo foi criado para designar locais 
na superfície da célula, com características moleculares específicas, em que determinadas substâncias interagem de forma pontual, semelhante ao modelo chave/fechadura. Erlich tem sido responsabilizado ainda pela introdução da farmacologia terapêutica, que, diferentemente da farmacologia experimental vigente a partir do século XIX, que testava drogas em animais sadios ou tecidos, passou a provocar doenças em modelos animais para testar drogas e medicamentos (Bosch, Rosich, 2008; Wheaterall, 1996).

A farmacologia foi definida por Schmiedeberg (citado em Dagognet, Pignarre, 2005, p.232) como uma ciência que estuda "os efeitos das substâncias químicas sob condições fisiológicas ..., que se ocupa da ação dos medicamentos independente de sua importância prática". Ainda que essa definição tenha guiado os primeiros passos da farmacologia, caracterizando-a como algo independente, é impossível separá-la da prática clínica e de outras áreas do conhecimento. Em definições mais recentes (Scheidlin, 2001, p.87) e como veremos na análise do livrotexto, essa é uma ciência inter-relacionada a outros saberes. Sua atuação tampouco pode ser dissociada da indústria farmacêutica, espaço social que interfere, com seus valores, na investigação científica e tecnológica.

Tomemos como exemplo o ácido salicílico. Do salgueiro (Salix alba), planta utilizada desde a Antiguidade para dores e problemas reumáticos, foi isolada a substância salicilina em 1829. No organismo, ela se converte em ácido salicílico, que por sua vez foi sintetizado em laboratório na segunda metade do século XIX para ser utilizado como analgésico (Pinto, 2008). Em 1893, o ácido salicílico teve sua estrutura modificada por Félix Hoffmann, funcionário da Bayer, para ácido acetilsalicílico (uma forma mais estável, que permitiu melhor administração e comercialização da droga, nessa época utilizada para dores, febres e problemas reumatológicos). Em 1899, o medicamento foi nomeado Aspirina ${ }^{\circledR}$ (Bayer, 2009; Dagognet, Pignarre, 2005; Pinto, 2008). Mesmo entrando para domínio público em 1919 (Dagognet, Pignarre, 2005) e, a partir daí, sendo comercializado por outras empresas sob seu nome químico, continuou conhecido como 'aspirina'. ${ }^{4}$ Esse talvez seja o medicamento mais famoso e difundido de todos os tempos. Sua inserção na vida das pessoas no Ocidente é tal, que talvez seja o único que conste em dicionários não médicos (Collins..., 1964, p.33, 479; Ferreira, 1980, p.183; Larousse, 2001, p.23; Merriam-Webster, 1966, p.28) como vocábulo usual. Pode-se dizer até que algumas vezes o termo 'aspirina' transformou-se em sinônimo de analgésico, de alívio da dor, sendo utilizado como metáfora para se referir a algo que atenua dores não físicas. Se houve a tentativa de definir o conhecimento farmacológico de maneira independente da produção de medicamentos (os produtos da técnica que a farmacologia tem gerado), parece que, na prática, essa separação é impossível.

\section{A farmacologia a partir do livro-texto: a primeira (1941) e a segunda (1955) edições}

A ênfase nos aspectos históricos sobre o desenvolvimento das drogas é característica marcante dessas duas edições, direcionadas a médicos. Outro aspecto pontuado na primeira edição é a importância da relação da farmacologia com diversas áreas do conhecimento. No prefácio, os autores afirmam: "Embora a farmacologia seja uma ciência médica básica em si mesma, recebe contribuições e contribui livremente com vários assuntos e técnicas de muitas disciplinas médicas, quer sejam clínicas ou pré-clínicas" (Goodman, Gilman, 1947 [1.ed. 1941], p.V.). 
Ainda no prefácio da primeira edição, Goodman e Gilman (1947 [1.ed. 1941], p.V) apontam os três objetivos da obra, repetidos nas demais edições: “(1) A correlação da farmacologia com as ciências médicas a ela relacionadas, (2) a reinterpretação das ações e usos das drogas a partir dos importantes avanços em medicina e (3) a ênfase nas aplicações da farmacodinâmica para a terapêutica".

Os autores comentam que a reinterpretação do uso das drogas antigas pode ser tão importante quanto o desenvolvimento das novas, pois podem surgir conhecimentos e olhares diferentes sobre as primeiras (Goodman, Gilman, 1947 [1.ed. 1941], p.V). O terceiro objetivo refere-se à farmacodinâmica, subárea da farmacologia. Para compreendê-lo, precisamos antes entender o que é a farmacologia segundo os autores. Conforme definido na seção I, capítulo 1 - "Princípios gerais", subtítulo "Abrangência da farmacologia", no primeiro parágrafo,

O assunto da farmacologia é amplo e inclui o conhecimento das fontes, propriedades químicas e físicas, composição, ações fisiológicas, absorção, destino e excreção, e o uso terapêutico das drogas. Uma 'droga' pode ser definida, de uma forma ampla, como qualquer agente químico que afete o protoplasma vivo ... Para o estudante de medicina e para o médico, no entanto, a abrangência da farmacologia e o número de substâncias a reconhecer como drogas são mais restritos do que a definição acima. O médico está interessado nas ações e nos usos das drogas na terapia da doença (Goodman, Gilman, 1947 [1.ed. 1941], p.3, destaque do original).

As subdivisões da farmacologia, segundo os autores, seriam a farmacognosia, a farmácia, a farmacodinâmica e a farmacoterapêutica. Eles apenas citam essas subdivisões, detendo-se na explicação das duas últimas, consideradas de interesse para os médicos, público-alvo da obra.

A farmacodinâmica é definida como

o estudo das ações das drogas no organismo vivo ... É uma das mais novas ciências médicas experimentais, e data somente do final da segunda metade do século XIX. ...é uma ciência limítrofe. Ela toma emprestados livremente temas e técnicas da fisiologia, química fisiológica, patologia e bacteriologia. Porém, é a única [dessas ciências] que tem sua atenção focada na ação das drogas. Como implica seu nome, seu assunto é de caráter dinâmico (Goodman, Gilman, 1947 [1.ed. 1941], p.4).

Vale destacar que a farmacodinâmica é vista como 'ciência limítrofe', não separada de áreas como a fisiologia e a patologia. Já está apontada a íntima relação da farmacologia, por meio dessa subárea, com a abordagem que no futuro servirá para o desenvolvimento de teorias que explicam o funcionamento fisiológico e fisiopatológico do organismo. Se pensarmos que a medicina se ocupa das doenças, e a biologia, do funcionamento dos seres vivos, que patologia e fisiologia estão ligadas a esses campos do conhecimento, respectivamente, e que a farmacologia aborda temas comuns a ambas, podemos levar em conta as considerações de Canguilhem (2006, p.153) e Jean Gayon (2006). Este se refere à epistemologia da medicina, com características próprias, que a distinguem da biologia. Embora ambas tenham como objeto lidar com a vida, para a biologia algumas alterações na fisiologia seriam adaptações, ao passo que para a medicina essas mesmas alterações podem ser consideradas patologias. Também nessa direção, Canguilhem (2006, p.169) lembra que, "se nos colocarmos no ponto de vista estritamente objetivo, não há diferença entre patologia e fisiologia", pois ambas lidam com condições de vida que seguem as mesmas leis físico-químicas. O que distingue os eventos 
considerados patológicos dos fisiológicos é o valor biológico que a eles se atribui (p.168), e esse valor não é objetivo sob o ponto de vista da ciência. Assim,

são os insucessos da vida [o que consideramos doença ou 'mau funcionamento'] que chamam - e que sempre chamaram - a atenção para a vida. ... É a própria vida, pela diferença que estabelece entre seus comportamentos ..., que introduz na consciência humana as categorias de saúde e doença. Essas categorias são biologicamente técnicas e subjetivas, e não biologicamente científicas e objetivas. ... Em resumo, a distinção entre a fisiologia e a patologia só tem, e só pode ter, um valor clínico (Canguilhem, 2006, p.170-171).

A farmacologia, embora trate das ações das substâncias em situações fisiológicas, se desenvolveu, principalmente, por causa das situações patológicas, ou seja, daquelas situações fisiológicas às quais foi atribuído um valor biológico negativo.

A farmacodinâmica, segundo Goodman e Gilman (1947 [1.ed. 1941], p.4-5), se ocupa (a) dos assuntos relacionados à absorção das drogas, locais de atuação e excreção no organismo, (b) da farmacologia comparativa (transposição de efeitos que ocorrem em animais de laboratório que possivelmente podem ocorrer no ser humano) e (c) da correlação da ação de uma droga com sua constituição química. Nas palavras dos autores, "Este é um campo que apenas começou a ser desenvolvido, a partir do qual provavelmente surgirão as maiores contribuições da farmacologia" (p.5). Aqui se aponta para uma área de estudo, ou forma de abordar o conhecimento sobre os medicamentos (correlacionando a estrutura química da substância com determinadas funções), que ainda não era prática corrente na época, mas já se vislumbrava. Embora alterações moleculares em drogas já conhecidas contribuam para o desenvolvimento de drogas com menos efeitos colaterais e atuações mais precisas em locaisalvo, vale lembrar que essa técnica tem sido utilizada para fins menos nobres. A indústria farmacêutica tem utilizado o artifício de promover mínimas alterações em uma molécula e, com isso, lançar novos medicamentos no mercado quando o medicamento mais antigo terminou o período de patente (Angell, 2007). Com isso, investe-se em marketing no novo medicamento, divulgando vantagens em relação àquele que perdeu a patente e que é muito parecido com o novo. Essas vantagens muitas vezes são pouco significativas, mas, com o investimento da divulgação junto aos médicos, são 'vendidas' como importantes, e os lucros da empresa tornam-se maiores, pois o novo produto passa a ser mais prescrito do que o anterior (Angell, 2007; Pignarre, 2001).

Sobre a farmacoterapêutica, última subdivisão da farmacologia, Goodman e Gilman (1947 [1.ed. 1941], p.5) declaram que

é o estudo do uso das drogas no tratamento da doença. ... não é mais praticada de uma maneira empírica, mas a terapia racional com drogas é baseada, 'sempre que possível', na correlação da ação farmacodinâmica das drogas com a fisiopatologia das doenças. Somente em casos excepcionais as drogas continuam sendo utilizadas sobre bases empíricas (destaque nosso).

Ainda que se tente fazer com que o uso das drogas seja baseado no conhecimento gerado no laboratório, sessenta anos depois o critério empírico persiste ao lado do científico. $\mathrm{Na}$ décima edição do livro, na seção "Princípios gerais", Nies (2001, p.45) afirma: 
Há um século, Claude Bernard formalizou os critérios para a coleta de informações válidas na medicina experimental. No entanto, a aplicação desses critérios para a terapêutica e o processo de tomada de decisões em relação à terapêutica têm sido, até recentemente, lentos e inconsistentes. Embora os aspectos diagnósticos da medicina sejam aproximados da sofisticação científica, as decisões terapêuticas muitas vezes são tomadas com base nas impressões e na tradição.

A segunda edição da obra (1955) tem basicamente as características da primeira (1941), embora os autores apontem para mudanças na área médica que se refletem na obra: "Os 14 anos que separam os dois livros testemunharam avanços farmacológicos e terapêuticos que provavelmente não têm paralelo na história da medicina. Quase todas as páginas do texto revelam esses progressos" (Goodman, Gilman, 1964 [2.ed. 1955], p.V).

No prefácio dessa edição, eles reafirmam os três objetivos que guiaram a anterior, acrescentando mais um:

Em função da acelerada velocidade com que novas drogas vêm sendo comercializadas para uso clínico, um quarto objetivo ganhou uma atenção proeminente, a saber, proporcionar ao leitor 'um modo de pensar sobre os medicamentos'. Dessa forma, o leitor vai estar mais bem preparado para resistir ao fluxo de apelos não comprovados que frequentemente é feito para [o uso] de novas drogas e para avaliar criticamente a literatura publicada sobre as propriedades e os usos de muitos agentes terapêuticos novos em comparação com outros compostos antigos, de uso bem estabelecido, da mesma classe (Goodman, Gilman, 1964 [2.ed. 1955], p.V).

Esse objetivo aparece também no prefácio da terceira edição (1965) de maneira explícita. Na quarta (1970) e quinta (1975) edições, alude-se a essa questão no prefácio, mas não como objetivo específico. A partir da sexta edição (1980) não há mais referência no prefácio sobre esse tópico.

A definição de farmacologia na segunda edição (1955) é idêntica à da primeira; as considerações sobre suas divisões também são mantidas, refletindo possivelmente que, apesar dos 14 anos decorridos, não houve mudança significativa no modo de pensar essa ciência. Uma das diferenças entre as duas edições (além da inclusão do quarto objetivo da obra) diz respeito a novas seções e novos capítulos, refletindo o resultado das pesquisas na área farmacológica.

Aparecem duas seções novas (a primeira edição tem 16 seções, e a segunda, 18): "Histamina e seus antagonistas" e "Drogas utilizadas na quimioterapia de doenças neoplásicas'. A histamina, já conhecida por ocasião da primeira edição, ganha destaque pelo surgimento dos anti-histamínicos, medicamentos amplamente pesquisados a partir da década de 1950. Ela pode ser utilizada como exemplo de substância que passa a ser explorada em busca de diferentes ações terapêuticas a partir do desenvolvimento de técnicas na área química e farmacológica após a Segunda Guerra Mundial. Vale a pena analisar a abordagem da histamina, porque reflete um passo diferente na caminhada da farmacologia: se na edição anterior essa substância aparecia como "uma droga [substância] de interesse acadêmico, mas de pouca importância terapêutica" (Goodman, Gilman, 1947 [1.ed. 1941], p.566), na segunda edição passa a nomear uma seção. Apesar de os autores declararem no início do capítulo que "A histamina continua um enigma para farmacologistas e fisiologistas" (Goodman, Gilman, 1964 [2.ed. 1955], p.644), o desenvolvimento de drogas anti-histamínicas já está estabelecido nessa edição: 
As razões pelas quais a histamina tem recebido ampla atenção são óbvias. O composto é um constituinte natural de muitos tecidos, tanto vegetais como animais, apesar do fato de não ter sido atribuído [a ele] um papel fisiológico definitivo. ... como resultado, têm sido introduzidos na terapêutica vários compostos que têm importantes aplicações terapêuticas, denominados anti-histamínicos (Goodman, Gilman, 1964 [2.ed. 1955], p.644).

Aqui é possível perceber que mesmo quando não há conhecimento sobre 'como' as coisas funcionam ou qual o mecanismo de ação da substância (histamina), há o desenvolvimento de um produto da técnica (medicamento anti-histamínico), que pode ser utilizado na terapêutica. A partir do uso clínico de substâncias que antagonizam a ação da histamina, surge o interesse em pesquisá-la e encontrar seus mecanismos de ação, ou seja, a partir de um resultado clínico, busca-se entender como agem a substância e seus antagonistas.

Em relação a outra seção nova dessa segunda edição, a que trata das drogas utilizadas para neoplasias, cabe ressaltar que os autores do livro-texto foram pesquisadores da área, estudando compostos a partir de um gás utilizado na Primeira Guerra Mundial (nitrogênio mostarda). A partir dele foram realizadas pesquisas e desenvolvidas drogas para o tratamento da leucemia. Nessa nova seção estão incluídas outras drogas citotóxicas, além de radioisótopos e hormônios.

\section{Mudanças que refletem a expansão da farmacologia: terceira, quarta e quinta edições $(1965,1970$ e 1975)}

Embora a terceira, quarta e quinta edições tenham peculiaridades, elas compartilham características comuns. A primeira é que, com a terceira edição, inaugura-se uma nova etapa do livro. Goodman e Gilman (1965, p.V) passam a ser os editores, e não os únicos escritores. No prefácio da terceira edição, lembram que essa medida foi necessária pelo grande volume de conhecimento gerado na área nesse período.

Além da mudança de autoria, o título do livro apresenta pequenas modificações nessas três edições: o subtítulo A textbook of pharmacology, toxicology, and therapeutics for physicians and medical students perde destaque nas terceira e quarta edições e é excluído na quinta edição. Essa modificação provavelmente reflete a expansão dessa área para outras profissões, que passam a estudar farmacologia e utilizar a obra como referência. A disposição das seções e capítulos é igual nas três obras, com mínimas alterações, totalizando 18 seções e 77 capítulos.

A terceira modificação que se inicia com a obra de 1965 e se mantém nessas três edições é a mudança de nome das seções que abordam as drogas de atuação no sistema nervoso central (SNC). O desenvolvimento da psicofarmacologia para tratamento de doenças psiquiátricas vem-se estabelecendo desde a segunda metade da década de 1950 e aparece no livro a partir dessa terceira edição. Nas anteriores havia duas seções relacionadas ao tema: "Drogas depressoras do SNC" e "Drogas estimulantes do SNC", totalizando 17 capítulos. Nas terceira, quarta e quinta edições essas seções passam a formar uma só, com o nome "Drogas que atuam no SNC", que inclui os capítulos das edições anteriores mais dois denominados "Drogas utilizadas no tratamento de doenças psiquiátricas" e "Dependência e abuso de drogas" (Drug addiction and drug abuse). Tais modificações refletem a projeção que as substâncias psicoativas passam a ter na abordagem biomédica e na sociedade (Goodman, Gilman, 1965). 
O prefácio da terceira edição começa reafirmando o boom da indústria farmacêutica, ao qual, posteriormente, vários autores da atualidade farão referência (Gerez, 1993; Giovanni, 1980; Greene, 2007; Healy, 1997) ao analisar o desenvolvimento de novas drogas após a Segunda Guerra Mundial. Goodman e Gilman (1965, p.V) afirmam que o quarto de século entre a primeira e a terceira edição do livro testemunhou a expansão das ciências biomédicas em escala sem precedentes.

São reforçados os quatro objetivos que constavam na segunda edição e, em função do quarto objetivo, "fornecer um modo de pensar sobre as drogas" (Goodman, Gilman, 1965, p.V), há a inserção do subtítulo "Guia para a selva terapêutica" na seção I dessa terceira edição. Esse subtítulo permanece até a décima edição (2001), é excluído na 11ª edição (2006), tornando-se uma questão não dita. Seu conteúdo inicia-se de forma praticamente idêntica nas demais edições:

O fluxo de novas drogas nos anos recentes tem proporcionado dramática melhora na terapia medicamentosa, mas também tem criado problemas ... Não é o menor deles a assim chamada 'selva terapêutica', expressão utilizada para referir-se à combinação entre o esmagador número de medicamentos, a confusão sobre a nomenclatura das drogas e a situação de incerteza associada a muitas delas. ... O médico pode contribuir para remediar essa situação prescrevendo produtos pelos seus nomes não comerciais. Mais importante, ele deve desenvolver um 'modo de pensar sobre drogas' com base nos princípios farmacológicos (Goodman, Gilman, 1965, p.33; destaques do original).

Também em todas as edições da terceira à décima, os autores pontuam no subtítulo "Guia para a selva terapêutica" que "somente uma pequena fração das novas drogas representa avanços importantes na terapêutica, e a eficácia e a segurança de uma nova droga só serão avaliadas após ela estar em uso clínico" (Goodman, Gilman, 1965, p.34).

Ainda no prefácio da terceira edição, os autores reafirmam sua intenção em manter o livro atrativo e de fácil consulta, sempre estabelecendo uma ponte entre a farmacologia básica e a medicina clínica. Apesar da múltipla autoria, lembram que a obra pretendeu continuar unificada, "um volume de múltiplos autores bem superior a uma série de contribuições individuais" (Goodman, Gilman, 1965, p.VI). Dos 42 autores, 23 foram alunos dos editores e permaneceram, em suas palavras, como "parentes de segunda geração" (p.V-VI). Goodman e Gilman destacam ainda o esforço para conservar o livro em um único volume e justificam o uso de "letras pequenas" como estratégia para alcançar essa meta:

sinceramente, é difícil justificar o uso da impressão grande e pequena; no entanto, com certas exceções, tipos reduzidos foram utilizados naquelas porções do texto que são menos relevantes, mas que se mantêm com alguma importância ... Por exemplo, 'a fascinante história das drogas', que em essência é uma parte estimulante da história da medicina, é apresentada dessa forma. ... Mas essa explicação parcial e superficial sobre os tipos menores não oferece conforto ao estudante ... Em última análise, ele deve confiar em seu julgamento e no conselho de seus professores para determinar qual material de texto é pertinente a seus interesses e necessidades (p.VI, destaque nosso).

É possível pensar em algumas questões ao nos deparar com o trecho citado, que abre essa edição. Nas primeira e segunda edições, há o uso de letras de tamanhos diferentes, mas não há explicitação de critérios para seu uso. Na terceira edição, começa a haver essa padronização 
que separa temas 'mais importantes' daqueles 'menos importantes'. Mesmo que cada leitor seja livre para escolher no texto as partes que julgue pertinentes, há um direcionamento, tanto pela explicação que os autores oferecem como pelo fato subjetivo de que aquilo que está em letra maior 'salta aos olhos'. Parece haver uma posição contraditória por parte dos editores, pois se, por um lado, os aspectos históricos do desenvolvimento das drogas são colocados em letras menores, por outro, reforça-se sua importância. Poderíamos considerar que na primeira edição não havia dúvida de que esses aspectos eram importantes, mas, nesse momento subsequente, há a necessidade de diminuir esse enfoque. Como ocorre na maioria das vezes, não é de uma hora para outra que o valor, ou importância social, de um tema diminui a ponto de ele ser substituído. A partir da quarta edição, não há mais referências às partes 'mais ou menos importantes'. A mensagem fica subliminar: se está em letras menores, é menos importante.

O conceito de farmacologia é ampliado na terceira edição, e assim se mantém nas duas seguintes, com o acréscimo de alguns atributos: "Em sua totalidade, a 'farmacologia' abrange o conhecimento da história, fonte, propriedades químicas e físicas, composição, efeitos bioquímicos e fisiológicos, mecanismos de ação, absorção, distribuição, biotransformação e excreção, e usos terapêuticos ou outros usos de drogas" (Goodman, Gilman, 1965, p.1, destaque do original).

Os autores complementam essa definição diferenciando as partes da farmacologia que interessam aos médicos e as que interessam às outras profissões, refletindo a transição dessa edição, que passa a ser direcionada não apenas aos médicos.

Se na segunda edição foi inserida a nova seção com o capítulo sobre histamina e drogas anti-histamínicas, nessa terceira edição há outra novidade: essa seção passa a ser chamada de "Autacoides" e ganha mais um capítulo intitulado "5-hidroxitriptamina e antagonistas; polipeptídeos - angiotensina e cininas" (capítulo 30). A inclusão das diferentes substâncias em uma mesma seção é assim justificada pelos autores: embora com funções díspares, elas "partilham um aspecto comum, a ocorrência natural no corpo" (Goodman, Gilman, 1965, p.614). Tanto a histamina quanto a serotonina (5-HT) são substâncias conhecidas há tempos, mas que passam a ganhar destaque na pesquisa farmacológica a partir da década de 1940. Os conceitos e funções dessas substâncias ainda não estão claros, conforme argumentam os autores:

autacoid, palavra derivada do grego autós (próprio) e akos (agente medicinal ou remédio). ... Qual o seu papel no corpo? Qual o seu valor como medicamento e qual o seu lugar na terapêutica? ... O fato certo pelo qual essas substâncias foram classificadas sob o título impreciso de 'autacoides' é, em certo sentido, uma confissão de que, no presente, a evidência não permite uma classificação funcional ... O problema, que se vai esclarecer em seguida, está mais relacionado ao excesso de hipóteses do que à carência delas (Goodman, Gilman, 1965, p.614-615).

Embora a falta de clareza esteja relacionada à ação específica dessas substâncias, isto é, vinculada à parte do conhecimento científico que lida com explicações para os fenômenos, ela acaba sendo secundária se comparada com a parte do conhecimento que lida com a busca de produtos técnicos (Lacey, 1998). Os medicamentos (anti-histamínicos) já estão sendo utilizados, mesmo que ainda não existam explicações sobre seu funcionamento. Assim acontece com a histamina e, posteriormente, com a serotonina. Se, por um lado, não há nada 
de estranho na busca de um produto da técnica para tratar uma dor ou problema de saúde considerado doença - esse sempre foi o papel daqueles que lidam com o sofrimento - por outro, a argumentação apresentada para a exploração dessas substâncias segue em outra direção: seria o conhecimento de sua ação que proporcionaria o desenvolvimento de novos fármacos. A serotonina foi investigada até que se encontrasse um medicamento capaz de atuar sobre alguma de suas ações (Healy, 1997), e, coerentemente com a ideia inicial de que ela faz parte de inúmeros processos, atualmente os inibidores seletivos da recaptação de serotonina (ISRS) são utilizados para resolver ou tratar 'quase tudo' (Turnquist, 2002; Bittencourt, 2010).

Nas quarta (1970) e quinta edições (1975), a definição de farmacologia corresponde à da terceira edição (1965), com a seguinte modificação: o trecho incluído na terceira edição, "outros usos de drogas", recebe na quarta edição um detalhamento. Nas palavras de Goodman e Gilman (1970, p.1; 1975, p.1): “O médico também está interessado nos agentes químicos que não são utilizados na terapia, mas são responsáveis por intoxicações domésticas e industriais, assim como pela poluição ambiental. ... Finalmente, todos os médicos partilham da responsabilidade de ajudar a resolver o problema sociológico contínuo do abuso de drogas".

Essa observação sobre problemas relacionados à poluição do ambiente ou ao abuso de drogas na introdução da Seção I mantém-se até a nona edição, em 1996. A décima edição (2001) não traz mais a referência explícita a esses problemas sociais.

Na quarta edição (1970), além de seu próprio prefácio, constam os das três edições anteriores. Há a sugestão de que o leitor se dirija a todos os prefácios para conhecer a trajetória do livro e a da farmacologia: "Cada edição surgiu num período estratégico. A primeira edição foi escrita quando a farmacologia básica ainda não havia atingido sua atual importância e não era completamente aceita pelos colegas clínicos como disciplina significativa ou relevante. O aparecimento deste livro contribuiu muito para modificar o quadro" (Goodman, Gilman, 1970, p.V).

No prefácio da quinta edição (1975) também há considerações sobre as edições anteriores, porém constam apenas os prefácios da primeira e da quinta edição, diferentemente do que aconteceu até a quarta edição. A partir dessa quinta edição, as questões relacionadas tanto à história das drogas quanto à interação da farmacologia com aspectos da vida social perdem espaço e não aparecem mais destacadas nos prefácios.

Surge aqui uma nova subdivisão da farmacologia, a farmacocinética, apresentada no prefácio (Goodman, Gilman, 1975, p.V). No capítulo "Princípios Gerais", há a definição da abrangência dessa nova subárea, que se mantém praticamente inalterada até a décima edição (2001): “A farmacocinética lida com a absorção, distribuição, biotransformação e excreção das drogas. Esses fatores, associados à dosagem, determinam a concentração da droga em seus sítios de ação, e, por consequência, a intensidade de seus efeitos em função do tempo" (Goodman et al., 1975, p.1-2).

Alguns dos atributos antes incluídos no campo da farmacodinâmica passam a fazer parte dessa nova subdivisão, que lida com a forma como a droga 'caminha' no organismo. Cabe à farmacodinâmica "o estudo dos efeitos bioquímicos e fisiológicos das drogas e seus mecanismos de ação", além da "correlação de sua estrutura química com seus efeitos e ações" (Goodman et al., 1975, p.2). Nos estudos de farmacocinética são identificadas e quantificadas as características da droga em si, seu tempo de duração no organismo até ser 
degradada ou até atingir o órgão-alvo. Na farmacodinâmica, pretende-se conhecer o modo de funcionamento da droga no organismo vivo, que processos ela desencadeia. Talvez a divisão em duas subáreas proporcione a redistribuição das pesquisas, que se expandem cada vez mais e demandam divisão de trabalho.

Também é possível visualizar outra questão: inicialmente a farmacodinâmica abordava as drogas e seus caminhos no organismo, e o foco principal era o indivíduo e seu organismo, receptores do medicamento. Com o surgimento da farmacocinética, o foco se divide: parte da farmacologia estuda a reação do organismo ao medicamento (a farmacodinâmica), e outra, o medicamento em si (a farmacocinética). Ao observar as várias edições do livro, percebe-se que, com o passar dos anos, a farmacocinética conquista espaço: o medicamento ganha 'vida própria', independente do organismo vivo. Como afirmam os autores, essa nova subdivisão é didática, mas seu aparecimento pode refletir o papel de destaque que os medicamentos passam a ter no processo terapêutico: no mínimo, dividindo o cenário com o paciente, que anteriormente detinha o papel principal.

Os anti-histamínicos, que apareciam desde a terceira edição como drogas promissoras, são citados no prefácio da quinta edição, com a expansão de seus usos a partir da identificação dos subtipos de receptores para a histamina (Goodman, Gilman, 1975, p.V). Vale destacar a citação do "receptor H2", mais uma vez indicando nova fase da abordagem farmacológica: as subdivisões de receptores para uma mesma substância, no intuito de identificar 'locais específicos' relacionados a funções fisiológicas. Essa identificação dos subtipos ocorreu a partir da observação da ação de alguns anti-histamínicos: os primeiros, atuantes em receptores H1, provocavam ação constritora nos brônquios e intestino; os seguintes, agindo sobre os receptores H2, com ação principalmente no estômago (Goodman et al., 1975, p.591-592). Nos anos seguintes, foram identificados outros subtipos na tentativa de encontrar drogas com ação 'ultraespecífica', evitando possíveis efeitos colaterais das substâncias. No decorrer das diferentes edições, outras substâncias terão seus subtipos explicitados a partir das pesquisas farmacológicas.

Com novos conhecimentos surgindo, o volume do livro aumenta a cada edição, tornando-o grande demais. A estratégia dos tipos grandes e pequenos parece não ser mais suficiente para limitar o tamanho da obra. Assim, "A fim de evitar a expansão da presente edição, áreas menos dinâmicas ou ultrapassadas foram condensadas ou eliminadas para permitir considerações adequadas de todos os avanços farmacológicos e terapêuticos importantes" (Goodman, Gilman, 1975, p.V). Não há especificação de quais foram essas áreas, mas poderíamos conjeturar que sejam os aspectos históricos, já que estes não mudam e recebem menos espaço quando observamos os textos a partir dessa quinta edição.

A quinta edição apresenta uma última novidade em relação ao contexto geral da obra: além da múltipla autoria, inaugurada na terceira edição (1965), Goodman e Gilman contam com o auxílio de editores associados: Alfred Goodman Gilman e George Koelle. Sobre este último, lembram que ele já participava da obra desde a terceira edição. O primeiro, filho de Alfred Gilman, é citado como representante da nova geração de farmacologistas (Goodman, Gilman, 1975, p.VI). Nos prefácios da terceira e da quarta edições, Goodman e Gilman (1965, p.V; 1970, p.VII) se referem à metade dos autores da obra como "antigos" alunos e companheiros de trabalho, e à outra metade como "parentes de segunda geração" (alunos 
de seus alunos). Já Alfred Goodman Gilman não é apenas filho de um deles: o "Goodman" que carrega em seu nome é uma homenagem ao referido livro. Ele próprio afirma:

O maior livro-texto de farmacologia, As bases farmacológicas da terapêutica, foi fruto da colaboração de Goodman e Gilman, publicado pela primeira vez em 1941. Eu também nasci em 1941 e fui chamado de Alfred Goodman Gilman. ... Como disse certa vez meu amigo Michael Brown, provavelmente eu seja a única pessoa que tenha sido nomeada segundo um livro-texto (Gilman, 1994).

Integrante da terceira geração de alunos dos autores iniciais da obra, Alfred Goodman Gilman parece compartilhar, além dos valores institucionais e sociais, os valores pessoais de Goodman e Gilman, por sua relação tão próxima com eles. De alguma forma, esse editor associado pode ser um dos fatores que mantém, nas edições seguintes, características que marcaram o início da obra. Entre elas, o modo como são apresentadas as definições dos temas, considerações sobre a indústria farmacêutica e cuidados com novos medicamentos, além da abordagem dos fatores históricos relacionados ao desenvolvimento de drogas. Mesmo que a cada edição este último aspecto tenha gradativamente menos enfoque, sua abordagem se mantém. Porém, na 11a edição, elaborada "pela primeira vez sem um Goodman ou um Gilman entre os autores ou editores" (Casavant, 2006, p.2791), os fatos históricos quase não aparecem, e o capítulo que trata da história da anestesia (presente desde a primeira edição) é excluído. Para Casavant (2006, p.2791), "alguma história se mantém" nessa edição. O aspecto histórico, característica importante na primeira edição, vai perdendo lugar na abordagem da farmacologia.

\section{Uma nova geração assume a farmacologia: sexta, sétima e oitava edições $(1980,1985,1990)$}

A década de 1980 foi palco de mudanças importantes na área da farmacologia (Angell, 2007). Iniciando sua quarta década de vida, o livro-texto, que na sexta edição (1980) reflete os acontecimentos da pesquisa e do desenvolvimento industrial dos cinco anos anteriores, tem seu título novamente modificado. Ele incorpora o nome de seus editores e autores das primeiras edições, passando a intitular-se Goodman and Gilman's: the pharmacological basis of therapeutics. Pouco antes do início da sétima edição (1985), em 1984, morre Alfred Gilman (Ritchie, 1996), e, na oitava edição (1990), Louis Goodman deixa de participar da obra, embora tenha vivido por mais dez anos. Alfred Goodman Gilman continua como editor com outros farmacologistas.

A definição de farmacologia permanece idêntica nessas três edições, praticamente inalterada em relação ao conceito apresentado na terceira edição. O destaque na sexta edição (1980) é para a importância que a farmacologia vem ganhando na formação e prática biomédicas, ressaltada no início de seu prefácio (Gilman, Goodman, 1983 [6.ed. 1980]). Em relação à estruturação das seções e dos capítulos, ocorrem modificações que se mantêm nas sétima (1985) e oitava (1990) edições. A Seção I, sobre farmacologia, ganha novos capítulos, e a intitulada "Ação das drogas nas junções neuroefetoras" deixa de ser a Seção IV para ser a Seção II, refletindo a ampliação da abrangência desse tema para a farmacologia. As novas tecnologias de pesquisa permitiram que se estudassem os mecanismos de ação das drogas 
também no SNC, antes de difícil acesso, questão também destacada no prefácio (Gilman, Goodman, 1983 [6.ed. 1980]).

O capítulo "Princípios da terapêutica" introduz de forma explícita "A terapia como uma ciência" (seu primeiro subtítulo) (Melmon, Gilman, Mayer, 1983, p.36), que implica o estudo das drogas em seres humanos. Esse tema é exposto pela primeira vez segundo os critérios dessa 'nova era' da farmacologia que caracteriza o que hoje conhecemos como 'farmacologia clínica'. Se, inicialmente, as 'cobaias' eram os próprios pesquisadores - como no caso do ópio, isolado em 1805 por Friedrich Serturner e experimentado em si mesmo (Scheindlin, 2001) - ou voluntários e pacientes (a partir da decisão do médico) - como no caso da penicilina (Friedman, Friedland, 2000) -, agora a farmacologia clínica institui os estudos controlados. ${ }^{5}$ Assim é feita sua apresentação:

A 'experimentação' nos seres humanos anteriormente era impossibilitada, e, geralmente, não era admitido que 'todo' tratamento por qualquer médico fosse e devesse ser planejado e, em algum sentido, registrado como um experimento. Embora deva existir sempre uma preocupação ética quanto à experimentação no ser humano, princípios têm sido definidos, e não há mais obstáculos éticos na coleta dos dados, experimentais ou de observação, em relação à eficácia de drogas em 'adultos' (Melmon, Gilman, Mayer, 1983, p.36; Blaschke, Nies, Mamelok, 1985, p.49, destaques do original).

A referência aos 'padrões éticos da experimentação humana' leva-nos a pensar quais seriam esses padrões que, embora 'aperfeiçoados' durante o século XX, têm permitido pesquisas que liberam medicamentos não tão seguros (em termos de eficácia ou de efeitos colaterais) como imaginamos que 'estudos controlados' o fariam. Angell (2007, p.128) lembra que "os laboratórios farmacêuticos publicam somente os resultados positivos, não os negativos" e que o controle sobre esses dados por parte dos órgãos de regulamentação fica prejudicado pelas várias estratégias desenvolvidas pelas empresas. Tal advertência não significa que esses laboratórios não tenham seguido rigorosamente os critérios técnicos e científicos para suas pesquisas, mas que são omitidos resultados considerados pouco relevantes naquele contexto e que passam a ser significativos no contexto da prática médica cotidiana, que não é a do laboratório. Ainda que não sejam o tema deste estudo, cabe mencionar que questões éticas têm exigido vigilância e regulação por parte da sociedade civil. Por exemplo, são inúmeros os casos de violação dos direitos humanos em pesquisas com medicamentos, tais como a utilização de prisioneiros nos campos de concentração na época do nazismo (Agamben, 2002) e estudos com a população civil na África na validação de tratamentos para o HIV e a Aids (Garrafa, Lorenzo, 2010).

De forma geral, as sétima (1985) e oitava (1990) edições continuam na perspectiva iniciada com a sexta edição, seguindo a mesma formatação e explorando a possibilidade de identificar novos locais de atuação e os caminhos dos medicamentos no organismo. No prefácio da sétima edição, os editores lembram uma nova era que se inicia na farmacologia: as técnicas desenvolvidas pela biologia molecular que permitem a clonagem de DNA e a biossíntese de produtos que passam a ser comercializados em larga escala, tais como a insulina humana e o hormônio do crescimento (Gilman et al., 1985, p.V.). A interação entre drogas é abordada como tópico específico, evidenciando que cada vez mais as pessoas utilizam múltiplos medicamentos, seja para tratar um mesmo problema de saúde, seja para diferentes problemas que coexistem. 
No prefácio da edição de 1990, há referência a drogas antes não disponíveis, tais como aquelas para o tratamento de infectados pelo HIV e medicamentos para baixar os níveis de colesterol (Gilman, 1990, p.V.). A farmacologia inaugura uma era de expansão que pode ser caracterizada como seu terceiro grande boom (o primeiro aconteceu com a síntese de substâncias no final do século XIX, e o segundo, após a Segunda Guerra Mundial). A habilidade técnica no desenvolvimento de novos medicamentos e a possibilidade de visualização de microestruturas no organismo biológico permitem o desenvolvimento de inúmeras drogas e a inferência de mecanismos causais a partir de modelos animais e dos testes clínicos. Essas inferências causais passam a ser usadas para explicar determinadas alterações fisiológicas que, no entanto, quando transportadas para situações clínicas, podem não ter a mesma validade se não é levado em conta o contexto (tanto biológico como social) em que os medicamentos são utilizados.

\section{A farmacologia no final do século XX e início do século XXI: nona, décima e 11 $1^{\text {a }}$ edições (1996, 2001 e 2006)}

A nona edição (1996) conta com a participação de Joel G. Hardman e Lee E. Limbird como editores chefe, Perry B. Molinoff e Raymond W. Ruddon como editores, e Alfred Goodman Gilman como editor consultor. A forma das seções e capítulos apresenta arranjos que diferem das edições anteriores, como, por exemplo, a presença de sinopses no início de cada capítulo; essa mudança de formatação é explicada no prefácio pelos editores (Hardman, Limbird, 1996, p.XIX). Como aconteceu nas terceira e sexta edições, as modificações na forma de organização da obra ocorrem por conta de novos conhecimentos produzidos. Hardman e Limbird destacam, ainda no prefácio, que "vários novos capítulos foram adicionados" (p.XIX), refletindo esse momento da farmacologia, em que uma nova categorização das drogas é apresentada como consequência de campos de investigação que ganham visibilidade a partir do final do século XX. Os editores exemplificam essa nova organização com os capítulos acrescentados como, por exemplo, sobre os princípios da terapia gênica e sobre a serotonina: “A identificação de diversos subtipos de receptores para serotonina e o esclarecimento dos papéis dos diferentes subtipos ... nos encorajaram a incluir um novo capítulo sobre agonistas e antagonistas de receptores de serotonina" (Hardman, Limbird, 1996, p.XIX).

A serotonina, que estava na seção "Autacoides" desde a terceira edição, a partir da nona faz parte da seção "Drogas atuando nas sinapses e nos locais de junções neuroefetoras". A justificativa para que a serotonina mereça capítulo exclusivo, apresentada no prefácio, é o fato da descoberta de seus subtipos no SNC (Hardman, Limbird, 1996, p.XIX). É certo que a serotonina saia do capítulo dos autacoides e vá para um lugar 'neutro', que trata da neurotransmissão em vários locais do organismo. No entanto, sua ação no SNC é destacada logo no início do resumo do capítulo 11, na décima edição (2001), justificada pela introdução dos novos medicamentos que atuam sobre essa substância e que têm sido utilizados para agir sobre "comportamentos complexos, tais como compulsão, agressão, ansiedade, depressão e ciclos de sono e vigília" (Sanders-Bush, Mayer, 2001, p.269). O destaque para o papel dessa substância no SNC, priorizado no texto e no contexto da obra, reflete a importância que vêm ganhando, a partir da década de 1980, os ISRS para distúrbios relacionados a comportamento e humor. 
A farmacologia também é redefinida nas duas últimas edições do livro-texto. Se na nona (1996) a definição se mantém como nas quatro precedentes (quinta, sexta, sétima e oitava), na décima (2001) essa definição 'regride'. É apresentado o conceito que constava na primeira edição de 1941, "como tributo aos autores originais" e "por manter sua validade" (Gilman, 2001, p.1). O que difere o conceito apresentado na nona edição daquele ampliado por Goodman e Gilman na quinta é a exclusão de atributos como o conhecimento relativo à história, aos mecanismos de ação e aos outros usos das drogas. A farmacocinética e a farmacodinâmica têm definiçõoes mais concisas, muito semelhantes às anteriores, com ênfase nos aspectos práticos da terapêutica.

Na 11a edição (2006), novamente o 'não dito': não há qualquer definição sobre farmacologia, tampouco sobre do que tratam a farmacodinâmica e a farmacocinética. Segundo Brunton (2006, p.XXI), a proposta é reduzir ao máximo o volume da obra, e, para isso, "os editores associados e eu trabalhamos para eliminar repetições e fatores externos. Pressionamos duramente os autores dos capítulos ... para esclarecer e condensar". Se a ênfase no aspecto histórico do desenvolvimento das drogas foi uma característica que contribuiu para o sucesso das primeiras edições, no decorrer dos anos houve mudança nesse sentido. Ele foi diminuindo significantemente a partir da nona edição (1996), a ponto de na 11ª (2006), a última, o capítulo "História da anestesia", presente em todas as anteriores, ter sido suprimido.

Os editores afirmam ainda que a fisiologia e a farmacologia básica são apresentadas em tipos maiores para que o estudante as localize com facilidade e que "o clínico e o especialista encontram detalhes nos escritos em tipo menor sob títulos identificáveis" (Brunton, 2006, p.XXI). Essa estratégia dos tipos grandes e pequenos, já utilizada, redefine o que importa ao estudante e ao especialista ou médico formado, sem, no entanto, explicar o que são os "detalhes" que interessam aos últimos. A tentativa é tornar a apresentação da farmacologia isenta de "fatores externos", um posicionamento diferente dos autores iniciais, que reforçavam a importância da relação dessa ciência com outras áreas do conhecimento.

\section{Considerações finais}

A primeira edição do livro-texto marca o início de uma época em que a farmacologia passa a fazer parte da formação dos profissionais médicos. Como afirmam seus autores, seu objetivo é instrumentalizar estudantes e profissionais para conhecer os medicamentos, esse recurso terapêutico amplamente utilizado na prática biomédica. A segunda edição mostra a expansão dessa ciência, logo após a Segunda Guerra Mundial. Esse período de mudanças significativas em todo o mundo teve reflexos na biomedicina e na produção e pesquisa de medicamentos. De acordo com Hobsbawm (1995, p.15), após uma “era de catástrofe", entre a Primeira e a Segunda Guerra Mundial, "seguiram-se cerca de 25 a trinta anos de extraordinário crescimento econômico e transformação social". Entre as grandes características dessa "era de ouro", está a expansão industrial. Para Hobsbawm (p.265), "as principais inovações que começaram a transformar o mundo assim que a guerra acabou talvez tenham sido as do setor químico e farmacêutico".

A farmacologia, ciência que estuda a ação de substâncias endógenas e exógenas no organismo, teve sua segunda grande expansão nessa época. Como ciência, está sujeita a 
valores próprios do conhecimento científico, assim como aos valores pessoais e sociais dos pesquisadores e do momento histórico. Desde os primórdios, uma das influências que recebeu foi da indústria farmacêutica, pois parte do seu desenvolvimento ocorreu dentro dela. Além de oferecer um produto para o tratamento de problemas de saúde, a indústria farmacêutica visa ao lucro, e esse aspecto não pode ser dissociado do desenvolvimento dos medicamentos. Essa indústria se expandiu, ganhou espaço na prática biomédica e trouxe riscos para ela, como afirmam Goodman e Gilman na segunda edição do livro-texto (1955). Eles referem, também, que a farmacologia é área do conhecimento que interage com outras, influenciando e recebendo contribuições de diversas ciências básicas e da prática clínica. Embora hipóteses teóricas e pesquisas com drogas influenciem o desenvolvimento de novos fármacos, quem determina quais situações são de sofrimento e merecem ser tratadas ou não com medicamentos ainda é a prática clínica. Conforme nos lembra Canguilhem (2006, p.170-171), "a distinção entre a fisiologia e a patologia só tem, e só pode ter, um valor clínico", ou seja, são os critérios clínicos que impulsionam o desenvolvimento da farmacologia.

Por outro lado, como outras ciências naturais, a farmacologia tem uma vertente que busca explicações para os fenômenos da natureza e um âmbito relacionado à manipulação da natureza (Lacey, 1998). Nessas duas direções em que caminha, a farmacologia tem contribuído mais no aspecto técnico-científico, de fabricar medicamentos úteis, do que trazendo explicações causais sobre a atuação dessas drogas. Por exemplo, mesmo que os pesquisadores tenham buscado entender a ação de substâncias como a histamina e a serotonina, os medicamentos atuantes sobre elas foram inseridos na prática clínica antes que essas ações fossem explicitadas. Não foi, portanto, o conhecimento farmacológico que indicou o uso inicial dos medicamentos para muitos dos problemas em que são utilizados; ao contrário, esse uso antecedeu o conhecimento sobre o modo de atuação dessas substâncias.

Os aspectos históricos foram tema valorizado por Goodman e Gilman quando escreveram as primeiras edições. No decorrer dos anos, essa abordagem foi perdendo espaço até desaparecer quase completamente em sua última edição. Este estudo reafirma a importância desses aspectos na divulgação científica da farmacologia, que, no caso do livro-texto analisado, é parte da formação dos profissionais médicos e da área da saúde. A 'não presença' nas últimas edições dos aspectos históricos referentes à descoberta dos medicamentos, assim como a exclusão de aspectos sociais e econômicos que envolvem o desenvolvimento da farmacologia e dos medicamentos, pode estar refletindo a interferência de fatores externos à própria farmacologia, como, por exemplo, a crescente influência da indústria farmacêutica, ainda que essa relação não apareça explicitamente na análise do livro-texto.

A abordagem do contexto histórico e social, assim como a valorização da relação da farmacologia com as ciências básicas e clínicas, relativizando o papel dessa ciência frente a outras áreas do conhecimento, como acontecia nas publicações iniciais do livro de Goodman e Gilman, certamente pode contribuir para uma terapêutica médica mais humanizada e mais completa. Este estudo chama a atenção para o desaparecimento desses aspectos nas últimas edições do livro-texto, tornando a apresentação da farmacologia isolada de um contexto social mais amplo, algo que na vida prática dificilmente ocorre. 


\section{NOTAS}

${ }^{1}$ Nessa e nas demais citações de textos em inglês, a tradução é livre. Para o inglês, drug (em português, droga ou medicamento), as autoras optaram por utilizar 'droga'.

${ }^{2}$ As 11 edições publicadas originalmente em inglês datam de 1941, 1955, 1965, 1970, 1975, 1980, 1985, 1990, 1996, 2001 e 2006. O livro foi também editado em várias línguas; até a oitava edição (1990), havia um intervalo entre a edição original e as traduções. A partir da nona edição (1996), ele passou a ser editado simultaneamente em vários idiomas, entre eles, polonês, espanhol, português e japonês. Neste trabalho, foram pesquisados os originais em inglês para todas as edições, exceto o da sexta (1980), por não ter sido encontrado. As primeira (1941), segunda (1955), terceira (1965) e quarta edições (1970), em inglês, foram adquiridas pelas autoras; as demais foram pesquisadas em bibliotecas e tiveram partes fotocopiadas. Apenas a sexta edição foi pesquisada somente em português. A cada citação no decorrer deste texto está sinalizada a referência bibliográfica de onde foi extraída. De forma geral, as citações foram feitas das obras originais em inglês, com tradução livre por uma das autoras. Quando o excerto foi retirado de obra em português, está assinalado em Referências. No caso de consulta a edição em português e em inglês, tendo havido divergência entre as traduções da autora e da edição em português, foi utilizada a primeira. Quando houve mais de uma impressão da mesma edição, optou-se por assinalar a data da impressão e da edição, como, por exemplo, no caso de Goodman, Gilman (1947 [1.ed. 1941]); trata-se da primeira edição de 1941, 15a impressão, de 1947.

${ }^{3}$ Curare é substância extraída de plantas - inicialmente utilizada por índios da América do Sul para banhar suas flechas, usadas na caça ou na guerra - que provoca paralisação reversível (Dagognet, Pignarre, 2005, p.104).

${ }^{4}$ A Bayer perde a patente desse medicamento, e outros laboratórios passam a produzi-lo e comercializá-lo. O nome químico, conforme lembram Schenkel, Mengue e Petrovick (2004, p.22-24), "é o nome do composto indicado como substância ativa. ... [Os nomes químicos] são importantes por ser os únicos que identificam uma substância de forma unívoca e a estrutura química de um fármaco. Por exemplo, Tylenol® e Dôrico® são nomes comerciais de uma substância que tem dois nomes genéricos, paracetamol ou acetaminofeno, e dois nomes químicos, 4-hidroxi-acetinilida ou N-acetil-p-aminofenol”.

${ }^{5}$ Os 'estudos (ensaios) clínicos controlados' podem utilizar a prova 'contra placebo', em que o medicamento em teste é comparado a um preparado sem efeito farmacológico. Pode ser também utilizado um medicamento que já tenha seu efeito determinado para o problema em questão no lugar do placebo. Nesses estudos, um grupo de pessoas recebe o medicamento em teste, e outro recebe o placebo ou medicamento que já foi testado para ver se aquele em teste tem algum efeito significativo sobre o problema a ser tratado. Ambos os estudos podem ser 'ensaios clínicos duplos-cegos', porque nem médicos (pesquisadores), nem pacientes (sujeitos da pesquisa) sabem quem usa o medicamento em teste ou o placebo (ou a droga já consagrada). Isso é feito para evitar o 'efeito placebo', ou seja, aquele efeito terapêutico que acompanha qualquer procedimento com intenção de tratar o doente e que não está relacionado diretamente à especificidade do tratamento, mas ao fato de o paciente se sentir tratado.

\section{REFERÊNCIAS}

AGAMBEN, Giorgio.

Homo sacer: o poder soberano e a vida nua. Belo Horizonte: Editora UFMG. 2002.

ALTMAN, Lawrence K.

Dr. Louis Goodman, 94, chemotherapy pioneer, dies. The New York Times, New York. Disponível em: http://www.nytimes.com/2000/11/28/us/drlouis-s-goodman-94-chemotherapy-pioneer-dies. html? pagewanted=2. Acesso em: 5 jan. 2010. 28 nov. 2000.

ANGELL, Marcia.

A verdade sobre os laboratórios farmacêuticos. Rio de Janeiro: Record. 2007.

BAYER.

Aspirin history. Disponível em: http://www. aspirin.com/scripts/pages/en/aspirin_history/ index.php. Acesso em: 4 maio 2010. 2009.
BITTENCOURT, Silvia C.

A "bíblia" da farmacologia e os antidepressivos: análise do livro texto de Goodman e Gilman: as bases farmacológicas da terapêutica de 1941 a 2006. Tese (Doutorado) - Centro de Filosofia e Ciências Humanas, Universidade Federal de Santa Catarina, Florianópolis. 2010.

BLACK, John.

Claude Bernard on the action of curare. British Medical Journal, London, v.319, n.7210, p.622. 1999.

BLASCHKE, Terence F.; NIES, Alan S.; MAMELOK, Richard D.

Principles of therapeutics. In: Gilman, Alfred Goodman et al. (Ed.). Goodman and Gilman's: the pharmacological basis of therapeutics. 7.ed. New York: Macmillan. p.49-65. 1985. 
BOSCH, Fèlix; ROSICH, Laia.

The contributions of Paul Erlich to pharmacology: a tribute on the occasion of the centenary of his nobel prize. Pharmacology, Basel, v.82, n.3, p.171-179. 2008.

BRUNTON, Laurence L.

Preface. In: Brunton, Laurence L. (Ed.); Lazo, John S.; Parker, Keith L. (Associated ed.). Goodman and Gilman's: the pharmacological basis of therapeutics. 11.ed. New York, McGraw-Hill. p.XXI. 2006.

BRUNTON, Laurence L. (Ed.); LAZO, John S.; PARKER, Keith L. (Associated ed.).

Goodman and Gilman's: the pharmacological basis of therapeutics. 11.ed. New York, McGraw-Hill. 2006.

CANGUILHEM, Georges.

O normal e o patológico. Rio de Janeiro: Forense Universitária. 1.ed. 1966. 2006.

CASAVANT, Marcel J.

Goodman and Gilman's The Pharmacological Basis of Therapeutics Digital Edition. Journal of the American Medical Association, Chicago, v.295, n.23, p.2791-2792. Disponível em: http://jama. jamanetwork.com/article.aspx?articleid=203008. Acesso em: 6 set. 2009. 2006.

CASAVANT, Marcel J.

Goodman and Gilman's the pharmacological basis of therapeutics. Journal of the American Medical Association, Chicago, v.288, n.16, p.2052. Disponível em: <http://jama.ama-assn.org/cgi/ content/full/288/16/2052>. Acesso em: 6 set. 2009. 2002.

COELHO, Edmundo Campos.

Físicos, sectários e charlatães: a medicina em uma perspectiva histórica comparada. In: Machado, Maria Helena. Profissões de saúde: uma abordagem sociológica. Rio de Janeiro: Editora Fiocruz. p.35-62. 1995.

COLLINS...

Collins English dictionary. London: Collins Glear Type Press. 1964.

DAGOGNET, François; PIGNARRE, Philippe. 100 mots pour comprendre les medicaments: comment on vous soigne. Paris: Les Empêcheurs de Penser en Rond. 2005.

FERREIRA, Aurélio Buarque de Holanda. Dicionário da língua portuguesa. Rio de Janeiro: Nova Fronteira. 1980.

FRIEDMAN, Meyer; FRIEDLAND, Gerald W. Alexander Fleming e os antibióticos. In: Friedman, Meyer; Friedland, Gerald W. As dez maiores descobertas da medicina. São Paulo: Companhia das Letras. p.243-276. 2000.
GARRAFA, Volnei; LORENZO, Cláudio. Helsinque 2008: redução de proteção e maximização de interesses privados. In: Caponi, Sandra et al. (Org.). Medicalização da vida: ética, saúde pública e indústria farmacêutica. Palhoça: Editora Unisul. 2010.

GAYON, Jean.

Epistemologia da medicina. In: Russo, Marisa; Caponi, Sandra (Org.). Estudos de filosofia e história das ciências biomédicas. São Paulo: Discurso Editorial. p.39-64. 2006.

GEREZ, José. C. Indústria farmacêutica: histórico, mercado e competição. Ciência Hoje, Rio de Janeiro, v.15, n.89, p.21-30. 1993.

GILMAN, Alfred Goodman (Ed.).

General principles: introduction. In: Hardman, Joel G.; Limbird, Lee E.; Gilman, Alfred Goodman (Ed.). Goodman and Gilman's: the pharmacological basis of therapeutics. 10.ed. New York: McGraw-Hill. p.1-2. 2001.

GILMAN, Alfred Goodman.

Autobiography. Disponível em: http:// nobelprize.org/nobel_prizes/medicine/ laureates/1994/gilman-autobio.html. Acesso em: 12 mar. 2010. 1994.

GILMAN, Alfred Goodman.

Preface. In: Gilman, Alfred Goodman et al. (Ed.). Goodman and Gilman's: the pharmacological basis of therapeutics. 8.ed. New York: Pergamon Press. 1990.

GILMAN, Alfred Goodman et al. (Ed.). Goodman and Gilman's: the pharmacological basis of therapeutics. 8.ed. New York: Pergamon Press. 1990.

GILMAN, Alfred Goodman et al. (Ed.) Goodman and Gilman's: the pharmacological basis of therapeutics. 7.ed. New York: Macmillan. 1985.

GILMAN, Alfred Goodman; GOODMAN, Louis S. Prefácio à sexta edição. In: Gilman, Alfred Goodman et al. (Ed.). Goodman e Gilman: as bases farmacológicas da terapêutica. Rio de Janeiro: Guanabara Koogan. p.V-VI. 6.ed. 1980. 1983.

GILMAN, Alfred Goodman et al. (Ed.). Goodman e Gilman: as bases farmacológicas da terapêutica. Rio de Janeiro: Guanabara Koogan. 6.ed. 1980. 1983.

GIOVANNI, Geraldo.

A questão dos remédios no Brasil: produção e consumo. São Paulo: Polis. 1980.

GOODMAN, Louis S.; GILMAN, Alfred.

Preface to the fifth edition. In: Goodman, Louis S. et al. (Ed.). The pharmacological basis 
of therapeutics: a textbook of pharmacology, toxicology and therapeutics for physicians and medical students. 5.ed. New York: Macmillan. p.V-VI. 1975.

GOODMAN, Louis S. et al. (Ed.).

The pharmacological basis of therapeutics. 5.ed. New York: Macmillan. 1975.

GOODMAN, Louis S.; GILMAN, Alfred. Preface to the fourth edition. In: Goodman, Louis S.; Gilman, Alfred (Ed.). The pharmacological basis of therapeutics: a textbook of pharmacology, toxicology and therapeutics for physicians and medical students. 4.ed. New York: Macmillan. p.V-VII. 1970.

GOODMAN, Louis S.; GILMAN, Alfred (Ed.). The pharmacological basis of therapeutics: a textbook of pharmacology, toxicology and therapeutics for physicians and medical students. 4.ed. New York: Macmillan. 1970.

GOODMAN, Louis S.; GILMAN, Alfred. Preface to the third edition. In: Goodman, Louis S.; Gilman, Alfred (Ed.). The pharmacological basis of therapeutics: a textbook of pharmacology, toxicology and therapeutics for physicians and medical students. 3.ed. New York: Macmillan. p.V-VI. 1965.

GOODMAN, Louis S.; GILMAN, Alfred (Ed.). The pharmacological basis of therapeutics: a textbook of pharmacology, toxicology and therapeutics for physicians and medical students. 3.ed. New York: Macmillan. 1965.

GOODMAN, Louis S.; GILMAN, Alfred. The pharmacological basis of therapeutics: a textbook of pharmacology, toxicology and therapeutics for physicians and medical students. New York: Macmillan. 2.ed. 1955. 1964.

GOODMAN, Louis S.; GILMAN, Alfred. The pharmacological basis of therapeutics: a textbook of pharmacology, toxicology and therapeutics for physicians and medical students. New York: Macmillan. 1.ed. 1941. 1947.

\section{GREENE, Jeremy A.}

Prescribing by numbers: drugs and the definition of disease. Baltimore: The Johns Hopkins University Press. 2007.

HARDMAN, Joel G.; LIMBIRD, Lee E.; GILMAN, Alfred Goodman (Ed.).

Goodman and Gilman's: the pharmacological basis of therapeutics. 10.ed. New York: McGraw Hill. 2001.

HARDMAN, Joel G.; LIMBIRD, Lee E. Preface. In: Hardman, Joel G. et al. (Ed.). Goodman and Gilman's: the pharmacological basis of therapeutics. 9.ed. New York: McGraw Hill. p.XIX. 1996.
HARDMAN, Joel G. et al (Ed.).

Goodman and Gilman's: the pharmacological basis of therapeutics. 9.ed. New York: McGraw Hill. 1996.

HASTINGS, Robert C.; LONG, Gillis W. Goodman and Gilman's: the pharmacological basis of therapheutics. Journal of the American Medical Association, v.265, n.20, p.2734-2735. Disponível em: http://jama.jamanetwork.com/ article. aspx ?articleid=386033. Acesso em: 6 set 2009. 1991.

HEALY, David.

The antidepressant era. Cambridge: Harvard University Press. 1997.

HOBSBAWM, Eric.

A era dos extremos: o breve século XX (19141991). São Paulo: Companhia das Letras. 1995.

LACEY, Hugh.

Valores e atividade científica. São Paulo: Discurso Editorial. 1998.

LAROUSSE.

Dictionnaire de poche. Paris: Larousse/HER. 2001.

MELMON, Kenneth L.; GILMAN, Alfred G.; MAYER, Steven E.

Princípios de terapêutica. In: Gilman, Alfred Goodman et al. (Ed.). Goodman e Gilman: as bases farmacológicas da terapêutica. Rio de Janeiro: Guanabara Koogan. p.36-49. 6.ed. 1980. 1983.

MERRIAM-WEBSTER.

The new Merriam-Webster pocket dictionary. New York: Pocket Books. 1966.

NIES, Alan. S.

Principles of therapeutics. In: Hardman, Joel G.; Limbird, Lee E.; Gilman, Alfred Goodman. Goodman and Gilman's: the pharmacological basis of therapeutics. 10.ed. New York: McGraw Hill. p.45-66. 2001.

NOGUEIRA, Conceição.

Análise(s) do discurso: diferentes concepções na prática de pesquisa em psicologia social. Psicologia: Teoria e Pesquisa, Brasília, v.24, n.2, p.235-242. 2008.

NOGUEIRA, Conceição.

A análise do discurso. In: Almeida, Leandro S.; Fernandes, Eugénia M. (Ed.) Métodos e técnicas de avaliação: novos contributos para a prática e investigação. Braga: CEEP. Disponível em: http://repositorium.sdum.uminho.pt/ bitstream/1822/4355/1/Capitulo_analise\%20 do\%20discurso_final1.pdf. Acesso em: 12 out. 2009. 2001.

OPS.

Organización Panamericana de la Salud. Primer informe sobre la enseñanza de la farmacología 
en las escuelas de medicina de la América Latina. Educación Médica y Salud, Washington, v.3, n.2, p.98-107. 1969.

ORLANDI, Eni P.

Scientific discourse and interpretation. Multiciência, Campinas. Disponível em: http://www.multiciencia.unicamp.br/ artigos_04/a_02_.pdfhttp://www.multiciencia. unicamp.br/artigos_04/a_02_.pdf. Acesso em: 12 out. 2009. 2005.

ORLANDI, Eni P.

Análise do discurso: princípios e procedimentos. Campinas: Pontes. 1999.

PIGNARRE, Philippe.

Comment la depression est devenue une epidemie. Paris: La Découverte et Syros. 2001.

PINTO, Angelo C.

Alguns aspectos da história da aspirina. Disponível em: http://www.sbq.org.br/filiais/ adm/Upload/subconteudo/pdf/Historias_ Interessantes_de_Produtos_Naturais05.pdf. Acesso em 23 dez. 2011. 2008.

PORTER, Roy.

Das tripas coração: uma breve história da medicina. Rio de Janeiro: Record. 2004.

PORTER, Roy.

Medical science. In: Porter, Roy. The Cambridge illustrated history of medicine. Cambridge: Cambridge University Press. p.154-201. 1996.

RITCHIE, Murdoch.

Alfred Gilman. In: National Academy of Sciences of the United States of America. Biographical memoirs. Washington: National Academies Press. 1996. Disponível em: http://www.nap.edu/html/ biomems/agilman.html. Acesso em: 06 set. 2009. 1996.
SANDERS-BUSH, Elaine; MAYER, Steven E. 5-hydroxytryptamine (serotonin): receptor agonists and antagonists. In: Hardman, Joel G.; Limbird, Lee E.; Gilman, Alfred Goodman. Goodman and Gilman's: the pharmacological basis of therapeutics. 10.ed. New York: McGraw-Hill. p.269-290. 2001.

SCHEINDLIN, Stanley.

A brief history of pharmacology. Modern drug discovery, v.4, n.5, p.87-88 e 91. Disponível em: http://pubs.acs.org/subscribe/archive/mdd/v04/ i05/html/05timeline.html. Acesso em: 9 fev. 2010. 2001.

SCHENKEL, Eloir P.; MENGUE, Sotero S.; PETROVICK, Pedro R. (Org.).

Cuidado com os medicamentos. Porto Alegre: UFRGS Editora. 2004.

TURNQUIST, Kevin.

Are we becaming a nation of depressives? The Humanist, Washington, v.62, n.5, p.27-33.

Disponível em: http://vnweb.hwwilsonweb.com/ hww/results/external_link_maincontentframe. jhtml?_DARGS=/hww/results/results_common. jhtml.16. Acesso em: 24 fev. 2008. 2002.

VAN DIJK, Teun A.

El análisis crítico del discurso. Anthropos, Barcelona, n.186, p.23-36. 1999.

VAN DIJK, Teun A.

A caminho de um modelo estratégico de processamento do discurso. In: Van Dijk, Teun A. Cognição, discurso e interação. São Paulo: Contexto. p.9-35. 1992.

WEATHERALL, Miles.

Drug treatment and the rise of pharmacology. In: Porter, Roy. The Cambridge illustrated history of medicine. Cambridge: Cambridge University Press. p.246-277. 1996.

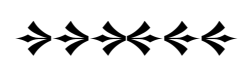

